\title{
Quantitative Backdraft Experiments
}

\author{
C. M. FLEISCHMANN \\ University of Canterbury \\ Christchurch, New Zealand \\ P. J. PAGNI and R. B. WILLIAMSON \\ University of California, Berkeley \\ Berkeley, CA 94720, USA
}

\begin{abstract}
This paper focuses on 17 experiments in a $1.2 \mathrm{~m}$ by $1.2 \mathrm{~m}$ by $2.4 \mathrm{~m}$ compartment. A methane burner, flowing at either $70 \mathrm{~kW}$ or $200 \mathrm{~kW}$, was ignited inside a closed compartment and burned until the initially available oxygen was consumed. After the fire self-extinguished, the burner was left on allowing the unburned fuel mass fraction in the compartment to increase. After removing a hatch, covering a $1.1 \mathrm{~m}$ wide by $0.4 \mathrm{~m}$ high slot opening, a gravity current entered the compartment. It traveled across the floor, mixed with the unburned fuel, and was ignited by a spark near the burner. After mixture ignition, a backdraft occurred as a deflagration ripped through the compartment culminating in a large external fireball. Histories recorded prior to backdraft included: fuel flow rates, upper layer temperatures, lower layer temperatures, upper layer species concentrations for $\mathrm{O}_{2}$, $\mathrm{CO}_{2}, \mathrm{CO}$, and $\mathrm{HC}$. Data collected to quantify the backdraft included opening gas flow velocities and compartment pressures. Results indicate that unburned fuel mass fractions $>10 \%$ are necessary for a backdraft to occur.
\end{abstract}

KEYWORDS: compartment fires, backdraft, fire initiation, explosion hazards

\section{INTRODUCTION}

The dangerous consequences of a backdraft are documented in numerous fire service publications and training manuals. ${ }^{1}, 2,3,4$ However, little research has been done in the area of backdrafts, and only recently has a scenario been presented describing the fundamental physics underlying backdraft phenomena ${ }^{5}$. A backdraft is defined as a rapid deflagration following the introduction of oxygen into a compartment filled with accumulated unburned fuel.

The scenario presented here assumes a fire in a closed room. The fire heats up the room, and leakage in the bounding surfaces minimizes the pressure differential. The hot layer descends 
over the fire as the oxygen concentration is reduced and the combustion efficiency decreases. Excess pyrolyzates accumulate in the upper layer forming a fuel rich mixture of low oxygen content. A small flame or glowing ember exists as a source of ignition. Suddenly, a new ventilation opening is provided and cold, oxygen rich, air enters the compartment and propagates across the floor as a gravity current ${ }^{6}$. Large scale mixing in the gravity current provides mixed zones within the flammable range that ignite when they contact an ignition source. Once ignited, a flame propagates through the compartment and drives the remaining unburned fuel out through the opening to burn outside the compartment in a spectacular fireball.

In this paper, experimental results are presented from a series of half scale experiments attempting to quantify backdraft. Experimental variables included fuel flow rate, burn time, ignition location, ignition delay time, burner height, species sample location, and opening size $^{7}$. This paper focuses on 17 experiments in which the opening geometry was a vertically centered, horizontal slot, in one end wall; the fuel source was a $0.30 \mathrm{~m}$ square burner, $0.30 \mathrm{~m}$ above the floor; and the ignition source was a spark located opposite the opening. Two different burner flow rates were used, $70 \mathrm{~kW}$ and $200 \mathrm{~kW}$. Data collected in these experiments had two goals: 1) to characterize the conditions in the compartment prior to backdraft and 2) to quantify the severity of the deflagration.

\section{EXPERIMENTAL DESIGN}

Apparatus: Experiments were conducted in a special compartment designed to safely control the dangerous overpressures expected in backdrafts. The experimental apparatus dimensions were limited to half a small residential room to minimize the expected hazard and to allow the experiments to be conducted inside a $900 \mathrm{~m}^{3}$ facility. Figure 1 shows a schematic of the apparatus giving the internal dimensions of the compartment and the locations of the instrumentation. In order to control the overpressure hazard, one long wall was a pressure relief panel designed according to refs. 8 and 9 . The interior surfaces of the compartment were lined with a $50 \mathrm{~mm}$ thick refractory fiber blanket installed over the gypsum wallboard on the walls and ceiling to provide the primary thermal resistance for the structure. A $0.9 \mathrm{~m}$ high by $1.5 \mathrm{~m}$ wide observation window of Neoceram ${ }^{10}$ was installed in the wall opposite the pressure relief panel.

To simulate a window or door, a $0.4 \mathrm{~m}$ high by $1.1 \mathrm{~m}$ wide opening was centered in the short wall opposite the burner, see Fig. 1. This opening was covered with a computer activated hatch which was opened after the fire had been burning for several minutes. A methane burner, $0.3 \mathrm{~m}$ square and $0.3 \mathrm{~m}$ high, was used in all of these experiments. The burner was placed against the wall opposite the opening, as seen in Fig. 1. A pilot flame was used to ignite the burner and was turned off $10 \mathrm{~s}$ after the start of the experiment. The primary ignition source for the backdraft was a spark ignitor located $0.45 \mathrm{~m}$ above the floor and centered over the top of the burner. For three of the experiments, the primary spark malfunctioned and the backup spark ignitor used to ignite the pilot light had to be used to ignite the backdraft. The backup spark was located $0.35 \mathrm{~m}$ above the floor and centered on the side of the burner facing the opening. A 10,000 volt transformer was used for each spark ignitor to produce an arc between two $3 \mathrm{~mm}$ diameter 308 stainless steel electrodes $5 \mathrm{~mm}$ apart. 


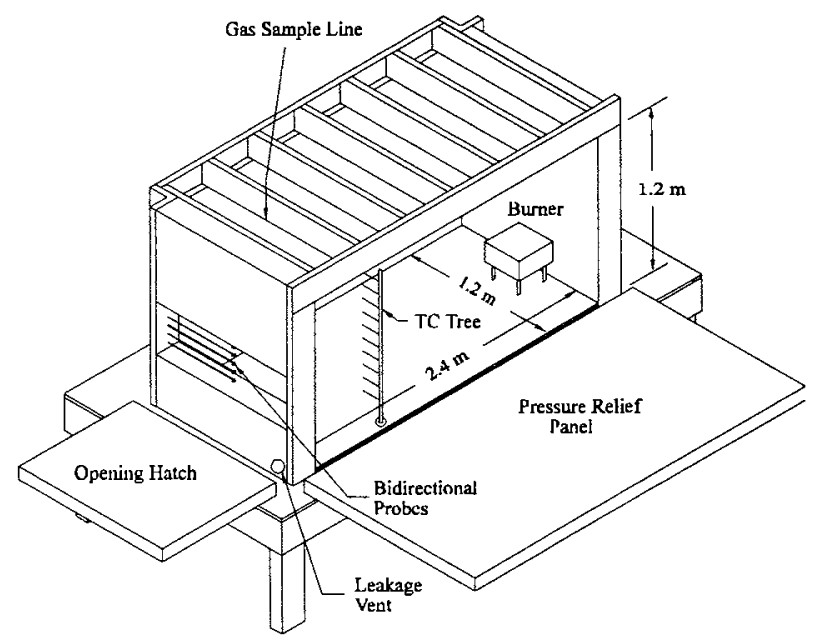

FIGURE 1 Sketch of the half scale backdraft compartment showing important features of the apparatus.

Every effort was made to seal all construction holes to control leakage. The primary sources of leakage into the compartment were found to be around the pressure relief panel and the opening hatch. A small $0.1 \mathrm{~m}$ diameter pressure relief vent was placed at the floor level to relieve the pressure from the initial burner ignition. A computer controlled cover closed over this vent $15 \mathrm{~s}$ after ignition. Additional details of the apparatus can be found in refs. 5 and 7.

Species Concentration: In order to characterize the compartment conditions prior to a backdraft, the species concentration histories in the upper layer were recorded. Gas concentrations measured were: oxygen $\left(\mathrm{O}_{2}\right)$, carbon dioxide $\left(\mathrm{CO}_{2}\right)$, carbon monoxide $(\mathrm{CO})$, and total hydrocarbons $(\mathrm{HC})$. Continuous gas samples were taken with stainless steel probes located $0.6 \mathrm{~m}$ from the opening wall, $0.2 \mathrm{~m}$ from the ceiling, and $0.6 \mathrm{~m}$ from the side wall.

The hydrocarbon sample required a separate heated sample line to prevent the loss of hydrocarbons due to condensation. A flame ionization detector was used to measure the hydrocarbon (methane) concentration. The expected hydrocarbon range was outside the limits of the analyzer and required dilution. Details of the dilution system and species balances performed can be found in Ref. 7.

Temperatures: A vertical thermocouple tree was placed $0.6 \mathrm{~m}$ from the opening wall and $0.2 \mathrm{~m}$ from the pressure relief panel, as shown in Fig. 1. The thermocouples were made from $0.5 \mathrm{~mm}$ type $\mathrm{K}$ thermocouple wire with a stainless steel overbraid. The average bead diameter was $1.1 \mathrm{~mm}$. The ten thermocouples were located at $0.10 \mathrm{~m}$ intervals, with the highest thermocouple at $0.15 \mathrm{~m}$ below the ceiling. The temperatures reported here are uncorrected values.

The thermal interface height history was calculated from the time dependent temperature profiles recorded from the thermocouple tree. The profiles were converted into unsteady 
average upper and lower layer temperatures using the method Quintiere et. al. ${ }^{11}$ applied to steady state temperature profiles.

Compartment Pressure: The compartment pressure history was recorded using an electronic pressure transducer with an effective range of 0 to $1250 \mathrm{~Pa}$. The pressure port was mounted in the stationary wall opposite the pressure relief panel at floor level. The ambient pressure reference was taken outside the building.

Hatch Flow: The flow in and out of the compartment after the hatch was opened was recorded using six bidirectional probes in the $\mathrm{h} / 3$ centered slot. The probes were located in the horizontal center of the opening, $65 \mathrm{~mm}$ apart, with the outer probes $43 \mathrm{~mm}$ from the soffit and sill. Probe velocities were calculated using the relationship given by McCaffrey and Heskestad. ${ }^{12}$ The mass flows were obtained by integrating the velocity and density profiles over the height of the opening.

Data Acquisition System: Data from each sensor was recorded using a HP VECTRA 80486-33 computer with an. 8 channel multifunction analog and digital input/output board. Two 32 channel analog input muliplexors were connected to this system. A total of 31 thermocouple and 17 voltage channels were measured. The system was capable of recording each channel 50 times a second. For experiments greater than $600 \mathrm{~s}$ the data was collected at a rate of $10 \mathrm{scan} / \mathrm{s}$ until $20 \mathrm{~s}$ before opening when the rate was automatically increased to 50 $\mathrm{scan} / \mathrm{s}$. The reduced scan rate for the initial period of the experiment was necessary to reduce the data file size.

\section{PROCEDURE}

Before each experiment a $60 \mathrm{~s}$ baseline was taken to record the initial conditions. A pilot flame was ignited at the burner $5 \mathrm{~s}$ before the start of the experiment. At $0 \mathrm{~s}$ a solenoid was opened on the methane flow to the burner and the clock was reset to zero. The burner was left on for a predetermined time period. Gas flow to the burner was terminated $5 \mathrm{~s}$ before the hatch was opened. In some of the experiments, a spark was left on the entire time, while in other experiments the spark was not turned on until the hatch was opened. When the spark was left on, a dancing flame would often appear and consume some of the available hydrocarbons making consistent results difficult to attain. In later experiments the spark remained off until the hatch was opened. The dancing flame phenomenon is discussed in ref. 5 .

\section{RESULTS}

$70 \mathrm{~kW}$ Fuel Flow Rate: The experimental parameters for the results presented in Figure 2 are: gas flow rate of $70 \mathrm{~kW}$, burner flow time of $775 \mathrm{~s}$, hatch opening at $780 \mathrm{~s}$, and backdraft ignition above the bumer. Figure $2 \mathrm{a}$ shows the upper layer species mass fraction histories for $\mathrm{O}_{2}, \mathrm{CO}, \mathrm{CO}_{2}$, and $\mathrm{HC}$. Idealized two-layer temperatures and height calculated from thermocouple tree data are shown in Fig. 2b. For the first $80 \mathrm{~s}$, the temperature in the compartment rises as the layer within the compartment descends over the fire. The $\mathrm{O}_{2}$ concentration is dropping as the fire consumes the available $\mathrm{O}_{2}$ and the $\mathrm{CO}_{2}$ concentration increases as a result of the combustion. Over the time period of $80 \mathrm{~s}$ to $170 \mathrm{~s}$ the temperature in the compartment drops as the fire is diminished. Over this same period the $\mathrm{HC}$ 


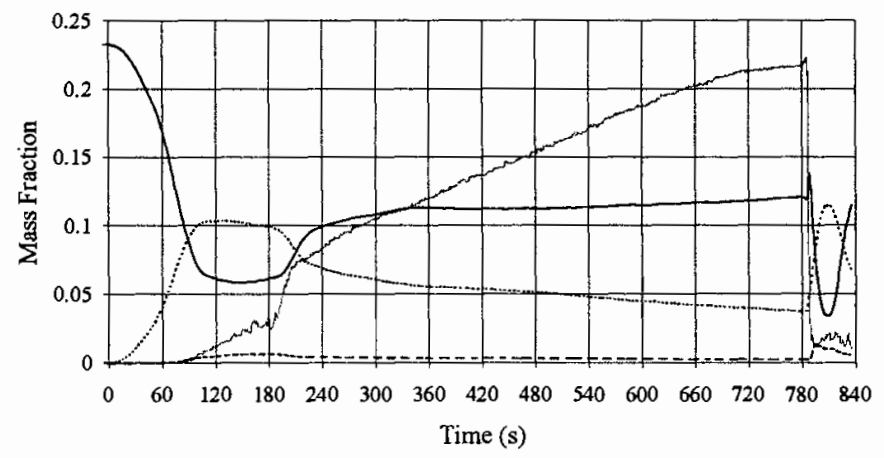

FIGURE 2a - Species concentration histories from backdraft experiment for $\mathrm{O}_{2}(-)$, $\mathrm{CO}(---), \mathrm{CO}_{2}(\cdots$.$) , and \mathrm{HC}(-\ldots)$ for the $70 \mathrm{~kW}(12$ th row in Table 1) fire source.

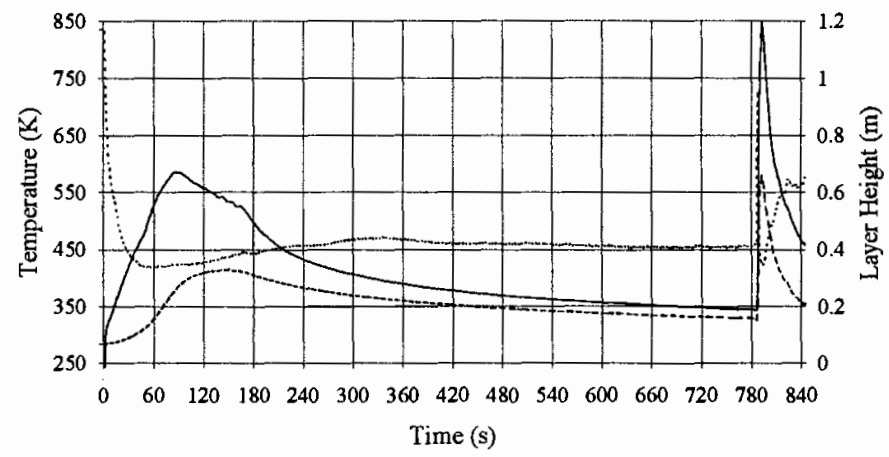

FIGURE 2b - Idealized two zone upper layer (-), lower layer (-- -), and layer height $(\cdots .$.$) histories from a 70 \mathrm{~kW}$ (12th row in Table 1) backdraft experiment.

concentration is starting to rise as the $\mathrm{O}_{2}$ and $\mathrm{CO}_{2}$ level off. The waviness seen in the upper layer temperature history over the range of $140 \mathrm{~s}$ to $170 \mathrm{~s}$ is the result of the flames pulsing before extinction. After $170 \mathrm{~s}$ the fire is completely out and the compartment begins to cool as seen in the exponential decay in the temperature profile. After $240 \mathrm{~s}$ the hydrocarbon concentration is steadily increasing. The oxygen concentration is slightly increasing as air leaks into the compartment and the $\mathrm{CO}_{2}$ concentration declines as compartment gases are lost by leakage. At $720 \mathrm{~s}$ the $\mathrm{HC}$ analyzer became saturated and the slope of $\mathrm{HC}$ concentration approaches zero. At $780 \mathrm{~s}$ the hatch is opened and a the gravity current enters the compartment. Once the gravity current reaches the ignition source, a flame travels through the mixed region, stirs the compartment, drives combustible gases out the hatch, and culminates in a large external fireball approximately $4 \mathrm{~m}$ in diameter. The spikes in the temperature shown in Fig. $2 \mathrm{~b}$ are caused by the wave propagation through the compartment. Gas concentrations after $780 \mathrm{~s}$ are unreliable due to the highly transient effects of the backdraft. 
The idealized two zone approximation is compared with the temperature data from the thermocouple tree at $80 \mathrm{~s}$ and $780 \mathrm{~s}$ in Fig. $2 \mathrm{c}$. At $80 \mathrm{~s}$ the compartment temperature is at its maximum and there is a substantial temperature gradient in the upper layer. The layer is located just above the burner surface. At opening, $780 \mathrm{~s}$, the layer is still near the top of the burner and the compartment temperature is nearly uniform vertically indicating that a one zone approximation is reasonable at this time. Figure $2 \mathrm{~d}$ is a photograph from this experiment taken $1.5 \mathrm{~s}$ after ignition. Notice the flame burning along the top of the gravity current.

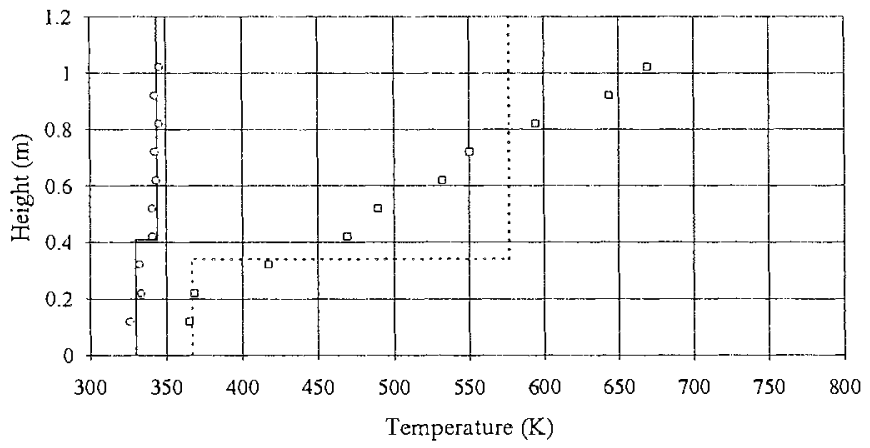

FIGURE 2c - Idealized two zone approximation compared with temperature data at $80 \mathrm{~s}(----, \mathrm{a})$ and $780 \mathrm{~s}(-, 0)$.

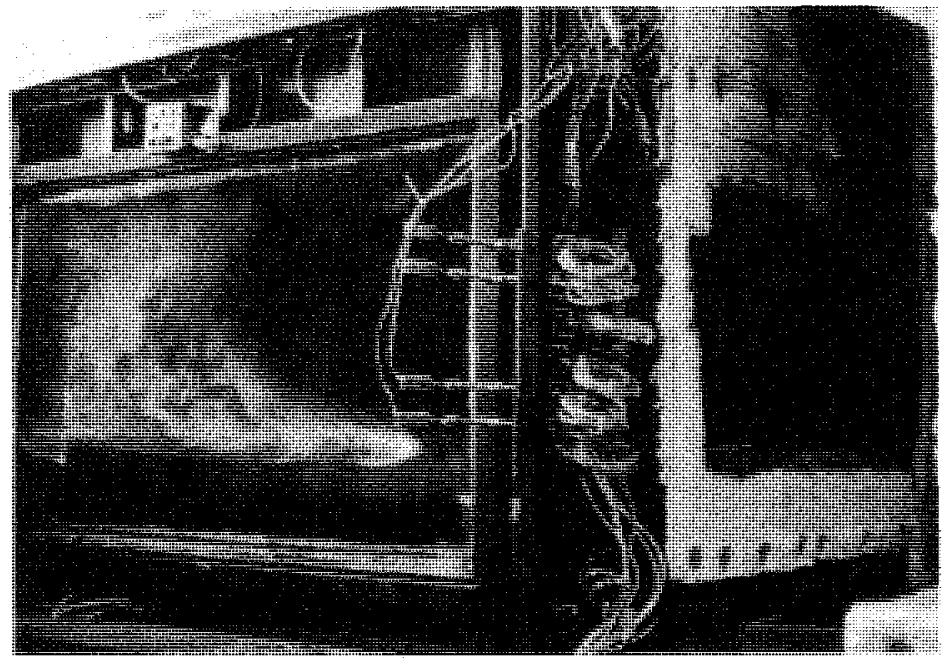

FIGURE 2d - Photograph showing flame structure for the same $70 \mathrm{~kW}$ fire source backdraft experiment. Photograph taken $1.5 \mathrm{~s}$ after ignition of the backdraft.

Figure 2e focuses on the effects of the backdraft, i.e., short histories for the compartment pressure and the total mass flow into the compartment. The time starts at opening, $780 \mathrm{~s}$ and shows a $20 \mathrm{~s}$ period during which the gravity current enters the compartment, a backdraft is 
ignited and a large fire ball exits the compartment and conditions relax to quasisteady equilibrium. At $780 \mathrm{~s}$ the compartment pressure drops as the hatch falls open. At $\sim 781.5 \mathrm{~s}$ the hatch strikes the table and causes a tremor in the pressure data. Ignition occurs at $785.6 \mathrm{~s}$, marked with a 1 in Fig. 2d. Flames exit the compartment at $787.5 \mathrm{~s}$ as the pressure reaches the first peak, marked with a 2 in Fig $2 \mathrm{e}$. The second peak is a result of the large fireball which exits the compartment. Even with the large indoor facility and approximately $11 \mathrm{~m}^{2}$ of vent area, the pressure rises significantly as a large fireball erupts outside the compartment. The large drop after the spike is a repercussion of the fireball. The negative total, not net, indicates mass flow into the compartment. After opening and prior to ignition, the total mass which flows into the compartment shows a steady increase. After ignition, the flow in the lower half of the opening is reversed and all of the flow is out of the compartment as indicated by the period of zero slope in Fig. 2e. Once the flame has left the compartment and the fireball has subsided, the mass flow rate into the compartment reaches a quasisteady state as indicated by the constant slope in the last $10 \mathrm{~s}$ of Fig. $2 \mathrm{e}$.

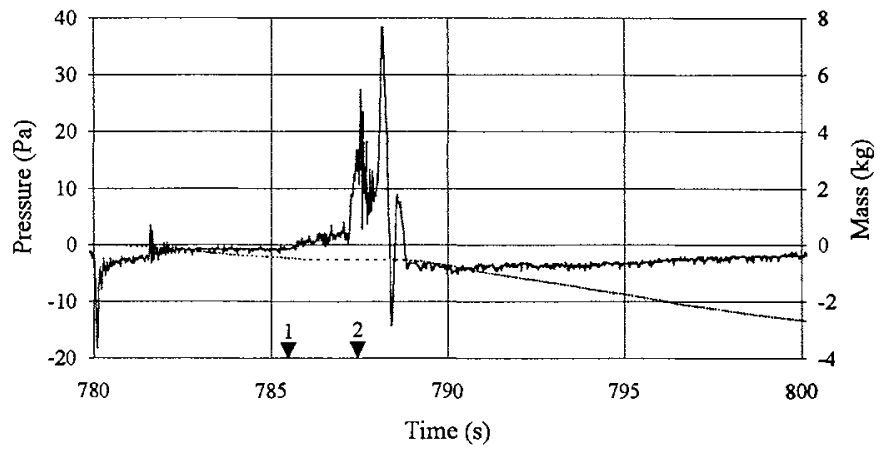

FIGURE 2e - Compartment pressure (-) and total mass inflow (….) histories for the same $70 \mathrm{~kW}$ fire source backdraft. Arrow 1 indicates ignition of the backdraft and arrow 2 indicates flame out the opening.

$200 \mathrm{~kW}$ Fuel Flow: Typical results from a $200 \mathrm{~kW}$ experiment are shown in Fig. 3 a-e with the following experimental parameters: burn time of $175 \mathrm{~s}$, hatch opened at $180 \mathrm{~s}$, and backdraft ignition by a continuous spark $0.15 \mathrm{~m}$ above the burner. Figure $3 \mathrm{a}$ shows the species mass fraction histories for the $\mathrm{O}_{2}, \mathrm{CO}, \mathrm{CO}_{2}$, and $\mathrm{HC}$ in the upper layer. Idealized two-layer temperatures and height are shown in Fig. 3b. As the temperature rises in the first $30 \mathrm{~s}$, the $\mathrm{O}_{2}$ concentration drops and the $\mathrm{CO}_{2}$ concentration increases. After $30 \mathrm{~s}$ the burning is reduced as the $\mathrm{O}_{2}$ reaches a minimum, the affects of the reduced burning can be seen in the declining $\mathrm{CO}_{2}$ concentration and temperature. The $\mathrm{HC}$ concentration starts to increase after $30 \mathrm{~s}$ and increases to approximately $12 \%$ at $113 \mathrm{~s}$ when a dancing flame ignites at the spark and moves around the floor of the compartment consuming hydrocarbons in the upper layer. The temperatures in the upper layer rise due to the dancing flame. The slow response time of the thermocouple tree causes the temperature rise to occur at $120 \mathrm{~s}$ instead of $113 \mathrm{~s}$ when the dancing starts. The dancing flame stops at $130 \mathrm{~s}$ when the oxygen in the lower layer is consumed and the hydrocarbons start to build again. 
At $180 \mathrm{~s}$ the hatch is opened and a the gravity current enters the compartment. At ignition the flame appears to propagate more through the main body of the gravity current rather than along the shear interface as seen in the $70 \mathrm{~kW}$ case. Then the flame exits the compartment and a large fireball approximately $2 \mathrm{~m}$ in diameter, considerably smaller than the $70 \mathrm{~kW}$ fireball, is produced. The spikes in the temperature shown in Fig. $3 \mathrm{~b}$ are caused by the flame propagation through the compartment. Gas concentrations after $180 \mathrm{~s}$ are unreliable due to the highly transient backdraft.

The idealized two zone approximation is compared with the temperature data from the thermocouple tree at $25 \mathrm{~s}$ and $180 \mathrm{~s}$ in Fig. 3c. At $25 \mathrm{~s}$ the compartment temperature is at its maximum and there is a substantial temperature gradient in the upper layer. The layer is located just above the burner surface. At opening, 180s, the layer is still near the top of the burner and the compartment temperature gradient is considerably reduced. Figure $3 \mathrm{~d}$ is a photograph showing the flame structure $1.5 \mathrm{~s}$ after ignition.

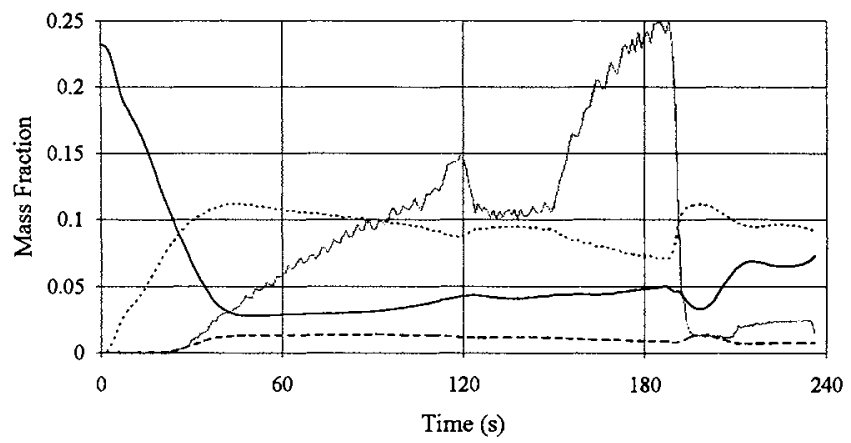

FIGURE 3a - Species concentration histories from backdraft experiment for $\mathrm{O}_{2}(-), \mathrm{CO}(-$ $--), \mathrm{CO}_{2}(\cdots \cdots)$, and $\mathrm{HC}(\ldots \ldots \ldots)$ for the $200 \mathrm{~kW}(15$ th row in Table 1) fire source.

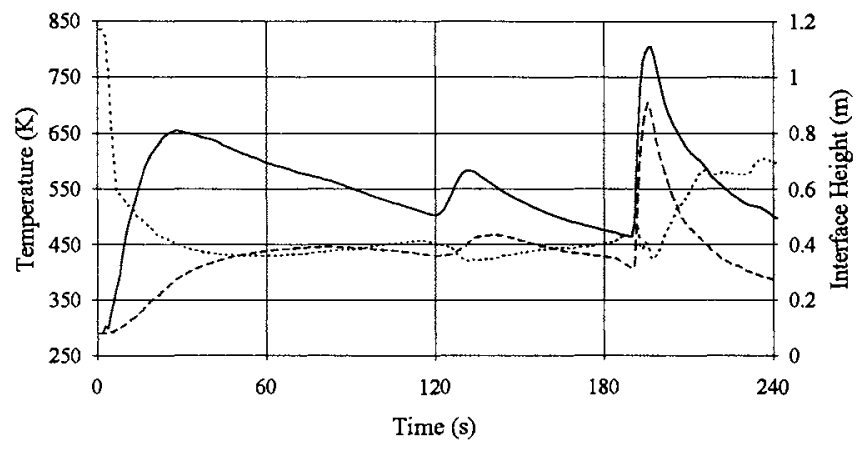

FIGURE 3b - Idealized two zone upper layer (-), lower layer $(--)$, and layer height $(\ldots .$.$) histories from a 200 \mathrm{~kW}$ (15th row in Table 1) backdraft experiment. 


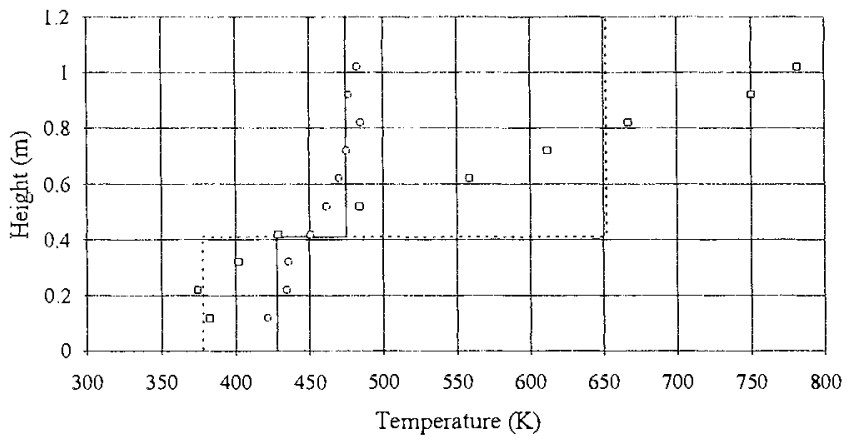

FIGURE $3 \mathrm{c}$ - Idealized two zone approximation compared with temperature data at $25 \mathrm{~s}$ $(-\ldots, \square)$ and $180 \mathrm{~s}(-,-, 0)$ for the same $200 \mathrm{~kW}(15$ th row in Table 1) backdraft experiment.

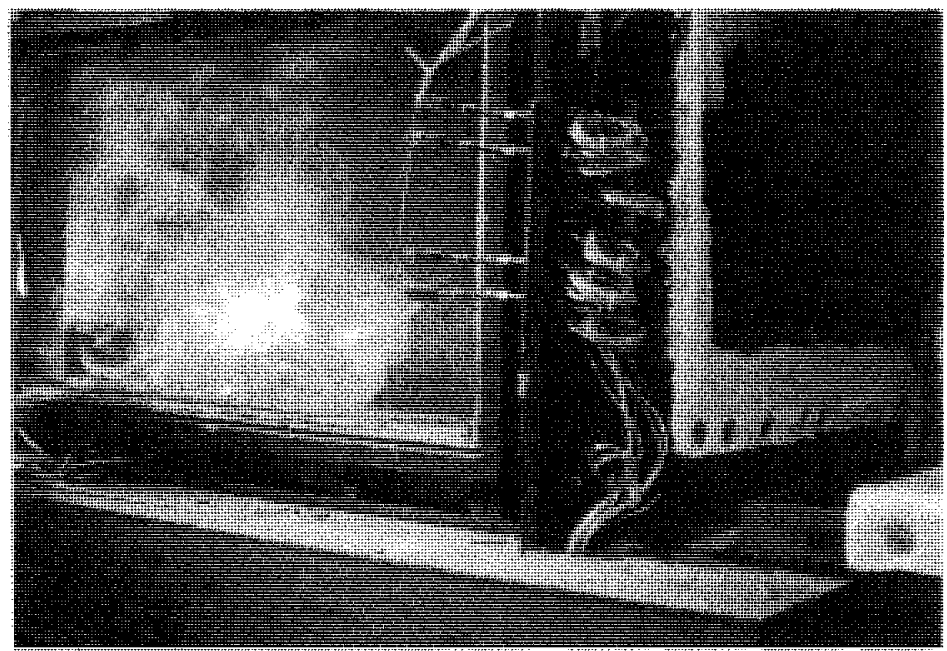

FIGURE 3d - Photograph showing flame structure for the $200 \mathrm{~kW}$ (15th row in Table 1) fire source backdraft experiment. Photograph taken $1.5 \mathrm{~s}$ after ignition of the backdraft.

Figure $3 \mathrm{e}$ shows the effects of a backdraft for the $200 \mathrm{~kW}$ fire source, i.e., histories for the compartment pressure and the total mass that has flowed in through the hatch since opening. The time starts at opening, $180 \mathrm{~s}$ and shows a $20 \mathrm{~s}$ period in which the backdraft is ignited and the fireball exits the compartment and conditions return to a quasisteady state. At $180 \mathrm{~s}$ the compartment pressure drops as the hatch falls open. At $\sim 181.5 \mathrm{~s}$ the hatch strikes the table and causes a tremor in the data. Ignition occurs at $186.7 \mathrm{~s}$ marked with a 1 in Fig. 3e. Flames exit the compartment at $189.2 \mathrm{~s}$, marked with a 2 in Fig $3 \mathrm{e}$, after the pressure has reached the first peak. As seen in the $70 \mathrm{~kW}$ case, the second peak in Fig. 3e is a result of the fireball outside the compartment. 


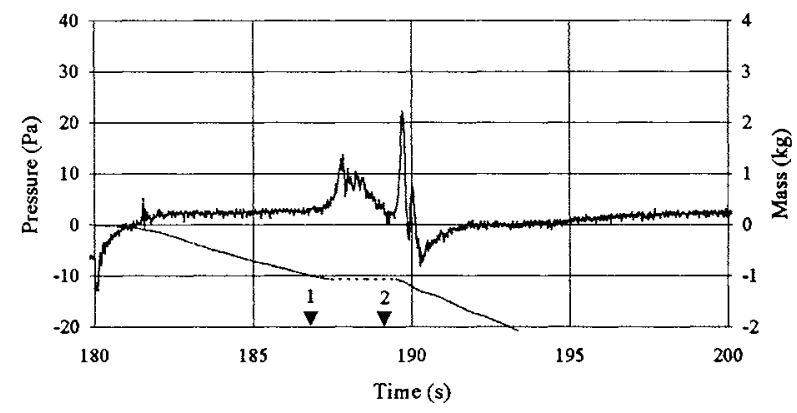

FIGURE 3e - Compartment pressure ( - ) and total mass inflow (.....) histories for the 200 $\mathrm{kW}$. Arrow 1 indicates ignition of the backdraft and arrow 2 indicates flame out the opening.

Summary: Table 1 is a summary of the 17 experiments reported here. Columns 1 and 2 are the burner characteristics, i.e., the burner flow rate and the time the burner gas is flowing. Columns 3 - 6 are the compartment species concentrations at opening for $\mathrm{O}_{2}, \mathrm{CO}, \mathrm{CO}_{2}$, and $\mathrm{HC}$, respectively. Columns $7-9$ are results calculated from thermocouple tree data for the lower layer temperature, the upper layer temperature, and the layer height at opening.

Column 10 is the observed ignition delay time. Values shown in parentheses were ignited by the burner edge spark; all other backdrafts were ignited by the spark $0.15 \mathrm{~m}$ above the burner. Column 11 is the peak pressure measured inside the compartment. Column 12 is the total mass carried into the compartment between hatch opening and subsequent ignition. Column 13 is an estimate of the diameter of the fireball which burns outside the compartment.

In order to obtain a quiescent environment within the compartment, the gas flow rate was set at the low value of $70 \mathrm{~kW}$ and the spark ignitors were left off until the hatch was opened. The flow rate was more difficult to control at the $70 \mathrm{~kW}$ rate and some minor fluctuation is seen in the data reported in column 1. Burn times ranged from $295 \mathrm{~s}$ to $775 \mathrm{~s}$. Times greater than $775 \mathrm{~s}$ were felt to be too hazardous to attempt safely. The species concentrations are nearly constant for $\mathrm{O}_{2}, \mathrm{CO}$, and $\mathrm{CO}_{2}$ indicating the repeatability of the system. The $\mathrm{HC}$ concentration histories are similar to Fig. 2 a with a long gradual build up, although the slope changed slightly depending on the bumer flow rate. The idealized two-layer temperatures decreased as the burner times increased due to the energy loss to the boundaries. Layer height maybe taken as constant throughout the $70 \mathrm{~kW}$ experiments considering the calculation method used. The maximum pressure and size of the fireball can be considered as gross measures of the intensity of the backdraft and are seen to increase with the $\mathrm{HC}$ concentration as expected.

Experiments were also conducted using a $200 \mathrm{~kW}$ fire source and varying the burn times from $115 \mathrm{~s}$ to $235 \mathrm{~s}$. In all five experiments, the spark ignitor was left on throughout the experiment and a dancing flame was observed in all but one experiment. The dancing flames caused large thermal instabilities within the compartment and increased mixing between the upper and lower layer. 
TABLE 1 - Summary data from backdraft experiments showing burner characteristics, Species concentrations at opening, idealized two-layer temperatures and height, ignition delay time, peak pressure, total mass flow into the compartment before ignition and fireball diameter.

\begin{tabular}{|c|c|c|c|c|c|c|c|c|c|c|c|c||}
\hline $\begin{array}{c}\text { Fuel } \\
\text { Flow } \\
(\mathrm{kW})\end{array}$ & $\begin{array}{c}\text { Burner } \\
\text { Time } \\
(\mathrm{s})\end{array}$ & $\mathrm{Y}_{\mathrm{O}_{2}}$ & $\mathrm{Y}_{\mathrm{CO}}$ & $\mathrm{Y}_{\mathrm{CO}_{2}}$ & $\mathrm{Y}_{\mathrm{HC}}$ & $\begin{array}{c}\mathrm{T}_{\mathrm{u}} \\
(\mathrm{K})\end{array}$ & $\begin{array}{c}\mathrm{T}_{1} \\
(\mathrm{~K})\end{array}$ & $\begin{array}{c}\mathrm{h}_{1} \\
(\mathrm{~m})\end{array}$ & $\begin{array}{c}\text { Ignition } \\
\text { Delay } \\
(\mathrm{s})\end{array}$ & $\begin{array}{c}\mathrm{p}_{\max } \\
(\mathrm{Pa})\end{array}$ & $\begin{array}{c}\mathrm{m}_{\mathrm{m}} \\
(\mathrm{kg})\end{array}$ & $\begin{array}{c}\text { Fire- } \\
\text { ball } \\
(\mathrm{m})\end{array}$ \\
\hline \hline 72 & 295 & 0.09 & 0.005 & 0.07 & 0.10 & 417 & 378 & 0.43 & 5.27 & 4 & 0.72 & 0 \\
\hline 72 & 355 & 0.11 & 0.004 & 0.06 & 0.12 & 390 & 361 & 0.43 & 5.36 & 6 & 1.05 & 2 \\
\hline 72 & 415 & 0.11 & 0.004 & 0.06 & 0.14 & 379 & 353 & 0.42 & 5.43 & 9 & 0.78 & 2 \\
\hline 72 & 475 & 0.11 & 0.003 & 0.05 & 0.16 & 362 & 339 & 0.42 & 6.63 & 28 & 0.91 & 3 \\
\hline 69 & 535 & 0.11 & 0.003 & 0.05 & 0.16 & 377 & 356 & 0.43 & 5.47 & 43 & 0.61 & 3 \\
\hline 77 & 535 & 0.11 & 0.003 & 0.05 & 0.20 & 363 & 344 & 0.41 & 5.67 & 40 & 0.69 & 4 \\
\hline 69 & 555 & 0.11 & 0.003 & 0.05 & 0.19 & 359 & 340 & 0.42 & $(3.7)$ & 73 & 0.46 & 4 \\
\hline 69 & 595 & 0.12 & 0.003 & 0.04 & 0.19 & 363 & 346 & 0.41 & 5.40 & 43 & 0.62 & 4 \\
\hline 73 & 655 & 0.12 & 0.003 & 0.04 & 0.21 & 350 & 331 & 0.43 & $(3.63)$ & 50 & 0.44 & 4 \\
\hline 71 & 715 & 0.11 & 0.003 & 0.04 & 0.20 & 348 & 332 & 0.44 & 5.63 & 33 & 0.66 & 4 \\
\hline 68 & 715 & 0.12 & 0.003 & 0.04 & 0.22 & 347 & 332 & 0.42 & 5.70 & 49 & 0.62 & 4 \\
\hline 70 & 775 & 0.12 & 0.002 & 0.04 & 0.22 & 344 & 330 & 0.41 & 6.60 & 39 & 0.52 & 4 \\
\hline 200 & 115 & 0.04 & 0.012 & 0.09 & 0.13 & 517 & 445 & 0.44 & 4.27 & 14 & 0.56 & 0 \\
\hline 200 & 145 & 0.04 & 0.012 & 0.10 & 0.10 & 570 & 475 & 0.34 & 6.27 & 8 & 0.93 & 1 \\
\hline 200 & 175 & 0.05 & 0.009 & 0.07 & 0.24 & 474 & 427 & 0.41 & 6.73 & 22 & 1.07 & 2 \\
\hline 200 & 205 & 0.06 & 0.008 & 0.06 & 0.29 & 447 & 408 & 0.43 & $(4.33)$ & 8 & 0.64 & 0 \\
\hline 200 & 235 & 0.06 & 0.007 & 0.06 & 0.29 & 433 & 400 & 0.43 & 5.27 & 36 & 0.96 & 4 \\
\hline
\end{tabular}




\section{CONCLUSIONS}

The results presented here show that the $\mathrm{HC}$ concentration must be $>10 \%$ in order for a backdraft to occur. When the HC concentration is $<10 \%$ the flame travel is slow and the compartment overpressure is much lower. As the $\mathrm{HC}$ concentration increases the compartment overpressure increases and the backdraft becomes more severe. The $70 \mathrm{~kW}$ burner flow rate experiments produced excellent backdrafts. The species concentrations show long slow changes. The results presented here suggest that the $200 \mathrm{~kW}$ source was too large for the compartment. Experiments with this large source were highly transient and compartment conditions are too unstable to interpret trends. The $200 \mathrm{~kW}$ experiments were further complicated by dancing flames due to the ignitors being on throughout the experiment.

Future work should concentrate on designing and building a full scale apparatus using a controlled fire source and possibly more realistic fuels. Improved gas analysis would also be useful to determine what hydrocarbons are present in the real fuel experiments. More realistic opening geometries could also be used to investigate the effects of typical doors and windows. Openings in the ceiling should also be incorporated to study the effects of firefighter ventilation tactics.

\section{ACKNOWLEDGMENTS}

National Institute of Standards and Technology, Building and Fire Research Laboratory, Grant No. 6ONANB1D1168 and 60NANB3D1438 partially supported this work. Assistance from J. Fleischmann, W. MacCracken, A. Revenaugh, N. Dembsey, C. Grant and C. Caldwell is appreciated

\section{REFERENCES}

${ }^{1}$ Croft, W.M., "Fires Involving Explosions", Fire Safety Journal, 3, 3-24, 1980/81.

${ }^{2}$ Steward, P. D. C., "Dust and Smoke Explosions", NFPA Quarterly, 7, 424-428, 1914.

${ }^{3}$ Fire Ventilation Practices. International Fire Service Training Association, Oklahoma, 32-33, 1970.

${ }^{4}$ Dunn, V., "Beating the Backdraft", Fire Engineering, 141, 44-48, 1988.

${ }^{5}$ Fleischmann, C.M., Pagni, P.J. and Williamson, R.B., "Exploratory Backdraft Experiments", Fire Technology, 29, 298-316, 1993.

${ }^{6}$ Fleischmann, C.M., Pagni, P.J. and Williamson, R.B., "Salt Water Modeling of Fire Compartment Gravity Currents", this symposium.

'Fleischmann, C.M., "Backdraft Phenomena", Doctoral dissertation in Fire Safety Engineering Science, University of California, Berkeley, 1993.

${ }^{8}$ Zalosh, R.G., "Explosion Protection", in SFPE Handbook of Fire Protection Engineering, (P.J. DiNenno, ed.) 2-88 to 2-105, National Fire Protection Association, Quincy, MA, 1988.

${ }^{9}$ Factory Mutual Engineering Corporation, "Damage-Limiting Construction," Loss Prevention Data Sheet 144, Norwood, MA, 1991.

10 "Neoceram Super Heat-Resistant Glass for Industrial Use," Nippon Electric Glass Co. Ltd.

${ }^{11}$ Quintiere, J.G., Steckler, K. and Corley, D., "An Assessment of Fire Induced Flows in Compartments" Fire Science and Technology 4, 1-14, 1984.

${ }^{12}$ McCaffrey, B.J. and Heskestad, G., "A Robust Bidirectional Low-Velocity Probe for Flame and Fire Application", Combustion and Flame, 26 125-127, 1976. 